\title{
Mitochondria as protean organelles: membrane processes that influence mitochondrial shape in yeast
}

\author{
Lenka Abelovska \\ Department of Biochemistry, Faculty of Natural Sciences, Comenius University, Mlynska dolina CH1, 84215 Bratislava, \\ Slovak Republic
}

\begin{abstract}
Yeast mitochondria constitute a complex dynamic tubular reticulum almost continually undergoing fission, fusion, and movements along cytoskeletal filaments. Besides machineries directly implicated in these processes, a large group of diverse proteins, whose exact contribution is still a matter of debate, also influence mitochondrial shape. This review focuses on those factors that seem to affect morphogenesis only indirectly, through their involvement in mitochondrial protein import, lipid supply, inheritance, or ion homeostasis. Many of them stand on the intersections of pathways contributing to mitochondrial biogenesis. Their absence has multiple phenotypic consequences, one of the most distinctive being the loss of the typical tubular shape of these organelles.
\end{abstract}

Key words: Mitochondria - Yeast - Mitochondrial morphology - Tubulation

\begin{abstract}
Abbreviations: CL, cardiolipin; ER, endoplasmic reticulum; ERMES, ER-mitochondria encounter structure; GEP, genetic interactors of prohibitins; IMM, inner mitochondrial membrane; IMS, intermembrane space; MDM, mitochondrial dynamics and morphology; MMM complex, Mdm10+Mdm12+Mmm1 (mitochore); mtDNA, mitochondrial DNA; OMM, outer mitochondrial membrane; PAM, presequence translocase-associated motor; PE, phosphatidylethanolamine; PL, phospholipid(s); SAM, sorting and assembly machinery; TIM, translocase of the inner membrane; TOM, translocase of the outer membrane.
\end{abstract}

\section{Introduction}

In the course of eukaryotic evolution, the ancestors of presentday mitochondria transformed from discrete, bacteria-like endosymbionts to very dynamic organelles of shapes, internal structure, size, and distribution that reflect cell's energetic, metabolic, and developmental conditions. Mechanisms underlying dynamics of these mitochondrial 'syncytia' might have primarily evolved to allow their proper segregation to daughter cells and their distribution throughout the cytosol, but became highly integrated into other cellular processes, eventually participating in the regulation of cellular homeostasis, adaptation, cell cycle progression, as well as death.

Mitochondrial biogenesis depends on nuclear genes, thus on protein transport from the cytosol, as well as on lipid supply

Correspondence to: Lenka Abelovska, Department of Biochemistry, Faculty of Natural Sciences, Comenius University, Mlynska dolina CH1, 84215 Bratislava, Slovak Republic

E-mail: abelovska@fns.uniba.sk from the endoplasmic reticulum (ER), where many steps of phospholipid (PL) biosynthesis occur. Defects or absence of mitochondrial proteins are often accompanied by a morphological change of mitochondria. Furthermore, mitochondrial shape alteration is not a mere symptom of damage, but may have a great impact on the cell and, in case of multicellular eukaryotes, also on the whole organism (Chan 2006; Detmer and Chan 2007). This review is focused only on the connections between morphogenesis of Saccharomyces cerevisiae mitochondria and several pathways contributing to biogenesis, inheritance, and ion homeostasis of these organelles.

\section{Mitochondrial morphogenesis - shape matters}

Mitochondria in actively growing yeast cells form a dynamic branched tubular reticulum, localized mainly close to the cell cortex (Hoffmann and Avers 1973). Their dynamics include frequent fission and fusion events, which control their number and partially also their shape (Bereiter-Hahn 
and Voth 1994), as well as the movement of these organelles along the actin filaments of the cytoskeleton, mainly during cell division (Boldogh et al. 2001). Moreover, several effects of mitochondrial dynamics on functions of these organelles were observed, mostly in mammalian cells (Chen et al. 2005; Benard et al. 2007; Jezek and Plecita-Hlavata 2009; Zorzano et al. 2010). Fusion and fission are also crucial for maintenance of their morphological as well as functional heterogeneity, including parameters like mitochondrial redox state, membrane potential $(\Delta \Psi)$, respiratory activity, uncoupling proteins, reactive oxygen species, and calcium (Kuznetsov and Margreiter 2009). In mammals, impairment of these 'morphogenetic' processes is often associated with pathological conditions such as optic atrophy or neuropathy (Chen and Chan 2009; Liesa et al. 2009). The morphogenetic players are collectively called shape proteins (Jensen 2005). Many of the corresponding genes have orthologs in organisms ranging from yeasts to mammals, except for those presumably involved in the so-called tubulation.

The first termosensitive mutants with defects in mitochondrial dynamics and morphology $(\mathrm{mdm})$ were obtained two decades ago (McConnell et al. 1990), 15 MDM genes were later identified in a screen of the yeast deletion library (Dimmer et al. 2002). Okamoto and Shaw (2005) proposed a classification based on the shape of affected mitochondria, thus discriminating mutants in fusion (small mitochondrial fragments), fission (complex mitochondrial network), and tubulation (one or two spherical mitochondria). Although these criteria are based on traits that can be discerned rather easily, the classification is still fairly problematic: mitochondrial shapes often vary throughout the cell population and are more complex, making it difficult to evaluate the nature of the impairment.

\section{Ambiguous concept of mitochondrial tubulation}

Mutants with large and spherical mitochondria lacking the typical tubular structures are usually called tubulation mutants, even though it has not been proved that the shape of their organelles is due to a defect in the process of tubulation itself.

Whereas fusion and fission are in principle well defined processes, the concept of mitochondrial tubulation remains unclear. Formation of tubular membrane structures was described in detail in the case of the plasma membrane undergoing endocytosis and of vesicle-mediated intracellular transport (Ren et al. 2006; Shibata et al. 2009; Graham and Kozlov 2010; Kozlov et al. 2010). It involves generation of membrane curvature, which is achieved either by disrupting the lipid composition symmetry of the two monolayers or by bending the membrane using constraints (protein scaffolding or wedging) or mechanical forces. The latter may be generated by molecular motors pulling out the membrane tubules along actin filaments, or by the polymerisation of actin filaments attached to the membrane.

Genes whose deletion in S. cerevisiae results in large spherical mitochondria, mostly devoid of cristae, include $M M M 1$, MDM10, and MDM12 (coding for subunits of a complex formerly called MMM complex, see below) as well as MDM34/ MMM2, MDM31, and MDM32 (Figure 1). Mmm1p is an integral ER membrane protein cooperating with the integral outer mitochondrial membrane (OMM) proteins Mdm10 and Mdm34, as well as the cytosol-oriented peripheral Mdm12p (Kornmann et al. 2009). Each of them functions in the assembly of several $\beta$-barrel proteins (Meisinger et al. 2006) and their complex is involved in attachment to the actin cytoskeleton (Hobbs et al. 2001; Boldogh et al. 2003; Meeusen and Nunnari 2003), as well as in mediating $\mathrm{Ca}^{2+}$ signalling and lipid exchange between mitochondria and ER by tethering the two organelles together (Kornmann et al. 2009) (see below).

The integral inner mitochondrial membrane (IMM) proteins Mdm31 and Mdm32 do not interact with the above-mentioned complex, but form two distinct and yet uncharacterized complexes likely to transiently interact with each other (Dimmer et al. 2005). The deletion of either one of the MDM31 and MDM32 genes is synthetically lethal with deletion of either one of the MMM1, MDM12, MDM10, and MDM34 genes (Dimmer et al. 2005). In addition, in $\Delta m d m 31$ and $\Delta m d m 32$ mutants, mitochondria remain attached to actin filaments, but the colocalization of the MMM complex with mitochondrial DNA (mtDNA) is rare and the nucleoids are misshapen, aggregated and destabilized (Dimmer et al. 2005; Kucejova et al. 2005) similarly as in $\Delta m m m 1$ (Hobbs et al. 2001) and $\Delta m d m 34$ (Youngman et al. 2004). Therefore, Mdm31p and Mdm32p were proposed to play a role in nucleoid anchoring via cooperation with the MMM complex. Together they might also contribute to a scaffold-like structure maintaining the tubular shape of the mitochondrion (Dimmer et al. 2005).

The MMM complex could participate in mitochondrial morphogenesis via interactions with yet unidentified cytoskeletal elements targeting the tubule formation in certain direction, or via organizing an unknown scaffold-like structure on the OMM surface which establishes and/or maintains the tubular shape (Okamoto and Shaw 2005). Yet, all these hypotheses remain speculative.

\section{Interconnection between mitochondrial shape and biogenesis}

As the aforementioned roles of Mdm proteins imply, mitochondrial biogenesis is not merely a result of parallel independent pathways supplying proteins and lipids. Rather, as summarized below, certain shape proteins contribute to several processes, thus complicating the identification of their 'primary' function (Figure 1, Table 1). 


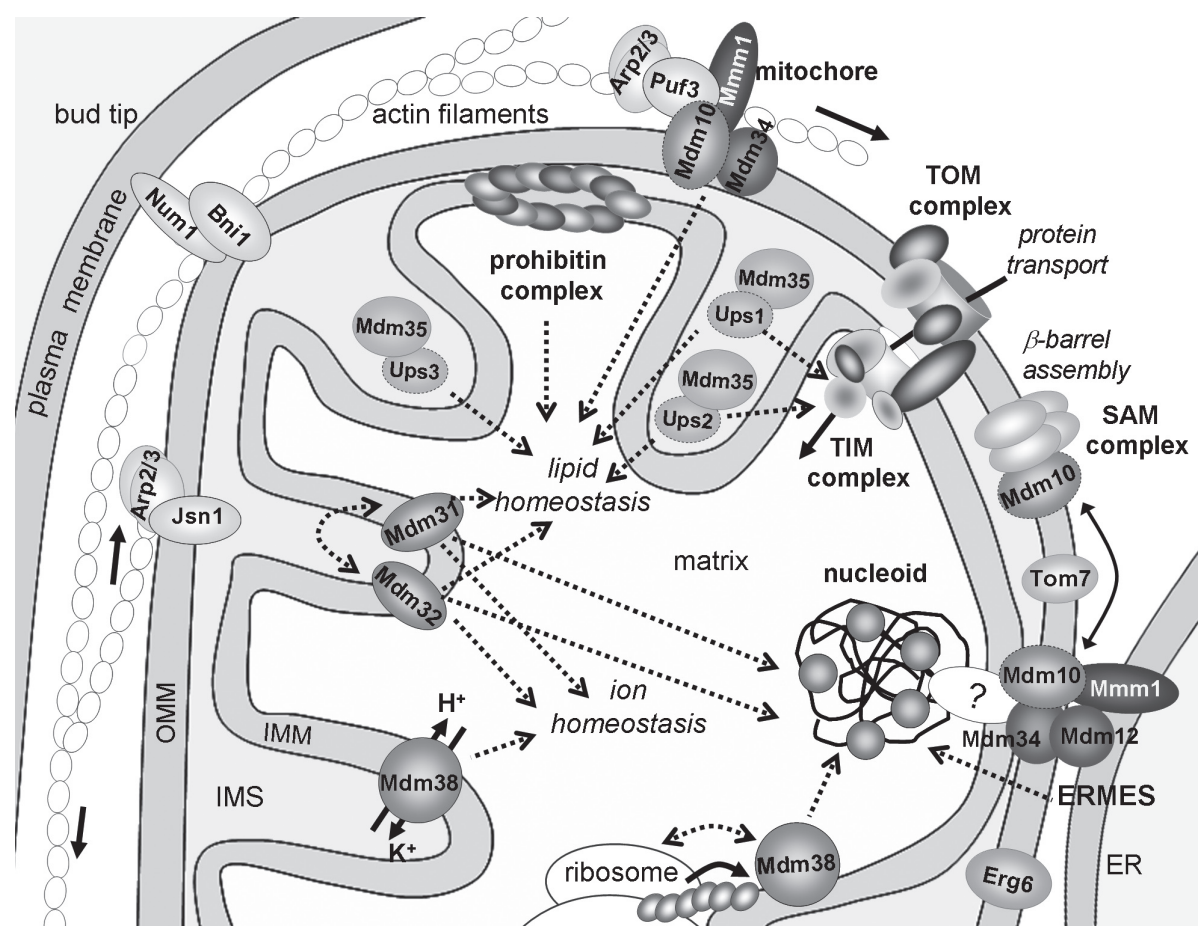

Figure 1. Most of the proteins, mentioned in this review, that influence mitochondrial shape, but their primary role is in processes other then fusion, fission, tubulation, cristae formation or lipid synthesis. Dotted arrows indicate proteins' influence (e.g. on stability of the nucleoid) and two-headed dotted arrows their interactions. Full arrows depict direction of movement. Proteins and cell components are not shown to scale.

\section{Protein import}

Two different protein import machineries operate in the OMM. The TOM (translocase of the outer membrane) complex recognizes and translocates almost all mitochondrial proteins. It is also sufficient for the proper insertion of most proteins with a simple topology into the OMM. However, $\beta$ barrel membrane proteins pass through the intermembrane space (IMS) bound to Tim9p/Tim10p chaperones and have to be integrated to the OMM by the sorting and assembly machinery (SAM) (Pfanner et al. 2004; Paschen et al. 2005).

The SAM core complex is able to properly sort the mitochondrial porin, but requires association with $\mathrm{Mdm} 10 \mathrm{p}$ to allow the dissociation of Tom40p from SAM (Meisinger et al. 2004; Yamano et al. 2010). The formation of the SAM holocomplex from SAM core and Mdm10p is modulated by Tom7p, which promotes segregation of Mdm10p from the SAM holocomplex into a low molecular mass form (Meisinger et al. 2006). This form of Mdm10p is available for association with another protein complex, which includes Mdm12p and $\mathrm{Mmm} 1 \mathrm{p}$, both also required for the assembly of all $\beta$-barrel proteins (Meisinger et al. 2007). Since the absence of this so-called MMM complex leads to the loss of the association of mitochondria with the cytoskeleton and with the ER, the complex was also designated as mitochore (Hobbs et al. 2001), or, if including also Mdm34p, as ER-mitochondria encounter structure (ERMES) (Kornmann et al. 2009).

Similarly to the nuclear kinetochore, the mitochore links the minimal heritable unit of mitochondria (i.e. mtDNA, OMM, and IMM) to actin filaments. It forms punctuate structures, some of which are localized in tight proximity of actively replicating mitochondrial nucleoids, at the OMMIMM contact sites (Hobbs et al. 2001; Boldogh et al. 2003; Meeusen and Nunnari 2003). In addition, the 2-10 links between mitochondria and the ER per cell provided by ERMES presumably facilitate localized calcium signalling, as well as PL exchange by membrane contact between these organelles (Kornmann et al. 2009). Moreover, in the bud, mitochondrial binding via the mitochore to actin filaments oriented toward the mother cell prevents the transport of the whole reticulum to the daughter cell (Fehrenbacher et al. 2004) (see below).

Besides lipid supply and actin binding, the association of ERMES with import complexes might contribute to the tubulation through targeting the protein import to growing sites of the mitochondrial reticulum and/or to the OMM/IMM contact sites (Jensen 2005). The loss of any of the ERMES components results in numerous phenotypic traits. The deletion mutants are inviable on non-fermentable carbon sources, contain one or few large spherical mitochondria with limited mobility and their mitochondrial nucleoids are disorganized, 
Table 1. Proteins influencing mitochondrial shape with supposed primary role in other processes

\begin{tabular}{|c|c|c|c|}
\hline Proteins & Process & $\begin{array}{l}\text { Mitochondrial morphology } \\
\text { prevailing in the mutant }\end{array}$ & Selected references \\
\hline \multicolumn{4}{|l|}{ Outer membrane* } \\
\hline Mdm10, Mdm12, Mdm34 & $\begin{array}{l}\text { protein import, } \\
\text { lipid supply by tethering to } \\
\text { ER, actin binding }\end{array}$ & large spheres & $\begin{array}{l}\text { Hobbs et al. 2001; } \\
\text { Boldogh et al. 2003; } \\
\text { Meeusen and Nunnari 2003; } \\
\text { Meisinger et al. 2007; } \\
\text { Kornmann et al. } 2009\end{array}$ \\
\hline Tom7 & protein import & $\begin{array}{l}\text { aggregates, } \\
\text { often fenestrated }\end{array}$ & Meisinger et al. 2006 \\
\hline Erg6 & lipid synthesis & fragments, aggregates & Dimmer et al. 2002 \\
\hline Num1, Jsn1, Puf3, Bni1, Bnr1 & inheritance & fragments, aggregates & $\begin{array}{l}\text { Fehrenbacher et al. 2005; } \\
\text { Garcia-Rodriguez et al. } 2007\end{array}$ \\
\hline essential & & & \\
\hline Tom22, Mim1, Sam35, Sam50 & protein import & collapsed, 'diffusive' structures & Altmann and Westermann 2005 \\
\hline Arp2/3, Myo2, Act1 & inheritance, movement & fragments, aggregates & $\begin{array}{l}\text { Boldogh et al. 2001; } \\
\text { Altmann and Westermann } 2005\end{array}$ \\
\hline Ncp1 & lipid synthesis & spheres & Altmann and Westermann 2005 \\
\hline \multicolumn{4}{|l|}{ Inner membrane } \\
\hline Mdm31, Mdm32 & ion homeostasis? & large spheres & $\begin{array}{l}\text { Dimmer et al. 2005; } \\
\text { Kucejova et al. } 2005\end{array}$ \\
\hline $\operatorname{Mdm} 38$ & $\begin{array}{l}\text { ion homeostasis, } \\
\text { protein import }\end{array}$ & small spheres & $\begin{array}{l}\text { Nowikovsky et al. 2004; } \\
\text { Froschauer et al. } 2005 ; \\
\text { Nowikovsky et al. } 2007\end{array}$ \\
\hline essential & & & \\
\hline Mge1, Pam18, Zim17 & protein import & collapsed, 'diffusive' structures & Altmann and Westermann 2005 \\
\hline \multicolumn{4}{|l|}{ Intermembrane space } \\
\hline Mdm35 & $\begin{array}{l}\text { protein import, } \\
\text { lipid supply }\end{array}$ & large spheres & $\begin{array}{l}\text { Tamura et al. } 2009 \\
\text { Potting et al. } 2010\end{array}$ \\
\hline Ups1 & lipid supply & $\begin{array}{l}\text { short tubules, small fragments, } \\
\text { aggregates }\end{array}$ & $\begin{array}{l}\text { Sesaki et al. 2006; } \\
\text { Tamura et al. } 2009\end{array}$ \\
\hline Ups2/Gep1 & lipid supply & spheres, small nets, aggregates & $\begin{array}{l}\text { Sesaki et al. 2006; } \\
\text { Tamura et al. } 2009\end{array}$ \\
\hline \multicolumn{4}{|l|}{ Endoplasmic reticulum ${ }^{* *}$} \\
\hline Mmm1 & $\begin{array}{l}\text { protein import, } \\
\text { lipid supply by tethering } \\
\text { to OMM }\end{array}$ & large spheres & $\begin{array}{l}\text { Hobbs et al. 2001; } \\
\text { Boldogh et al. 2003; } \\
\text { Meeusen and Nunnari 2003; } \\
\text { Meisinger et al. 2007; } \\
\text { Kornmann et al. } 2009\end{array}$ \\
\hline Mdm2/Ole1 & lipid synthesis & aggregates & $\begin{array}{l}\text { McConnell et al. 1990; } \\
\text { Stewart and Yaffe 1991 }\end{array}$ \\
\hline $\begin{array}{l}\text { Erg24, Erg28 } \\
\text { essential }\end{array}$ & lipid synthesis & fragments, aggregates & Dimmer et al. 2002 \\
\hline Erg1, Erg7Erg13, Erg25, Erg26, Erg27 & lipid synthesis & spheres & Altmann and Westermann 2005 \\
\hline \multicolumn{4}{|l|}{ Cytosol, essential ${ }^{* *}$} \\
\hline Erg8, Erg10, Erg12, Mvd1 & lipid synthesis & spheres & Altmann and Westermann 2005 \\
\hline
\end{tabular}

* inside, associated with, or bound to an OMM protein

${ }^{*}$ some of the proteins have, in addition, another localization than the one mentioned here

leading to mtDNA destabilization (Sogo and Yaffe 1994; Berger et al. 1997; Hobbs et al. 2001; Hanekamp et al. 2002).

As revealed in a screen examining mitochondrial shape changes after repression of essential genes, several essential components of the protein import machinery influence mitochondrial morphology as well. Under depletion of Tom 22p (component of the TOM complex), Mim1p (required for TOM complex assembly), Sam35p, Sam50p (subunits of the 
SAM complex), Mge1p, Pam18p, or Zim17p (components or cofactors of the TIM23 translocase and its associated import motor), mitochondria collapse into a rather diffusive-appearing structure (Altmann and Westermann 2005). Deletion of the nonessential TOM7 leads to aggregated, often fenestrated mitochondria that are unevenly distributed in the cell (Dimmer et al. 2002). All these proteins presumably contribute to morphogenesis by sustaining sufficient levels of some shape proteins in mitochondria (Altmann and Westermann 2005).

\section{Phospholipid supply}

Recently, Zheng and collaborators demonstrated that mitochondria do not contain lipid rafts (Zheng et al. 2009). However, the large ring-like supercomplexes formed by prohibitins in the IMM are supposed to act as membrane organizers, presumably enclosing microdomains of the bilayer enriched in cardiolipin (CL) and phosphatidylethanolamine (PE) (Osman et al. 2009), possibly functionally similar to the plasma membrane rafts. The yeast prohibitin complex is required to stabilize some products of mitochondrial translation (Nijtmans et al. 2000) and protects the native peptides from degradation by $m$-AAA proteases, assembling into large supercomplexes with these enzymes (Steglich et al. 1999). Its components, Phb1p and Phb2p, might form a scaffold recruiting particular proteins to a specific lipid environment required for their function or, on the contrary, enclose protein-free membrane domains, possibly present at IMM-OMM contact sites (Osman et al. 2009).

Prohibitins become essential under CL or PE depletion. Their absence is synthetically lethal with the deletion of one of at least 35 genes (named GEP for genetic interactors of prohibitins), the majority of which disturb PE and/or CL levels upon deletion (Birner et al. 2003; Osman et al. 2009). Some of the Gep proteins (e.g. the MMM complex components) presumably assist in the insertion of OMM proteins affecting mitochondrial lipid biosynthesis, while others may carry out a direct role in lipid metabolism or its regulation. In addition to these genetic interactions, $\mathrm{PHB} 2$ acts as a multicopy suppressor of the absence of Mdm12p or Mdm10p (Berger and Yaffe 1998).

In the context of lipid metabolism, only two GEP genes, UPS1 and UPS2/GEP1, were studied in more detail (Sesaki et al. 2006; Osman et al. 2009; Tamura et al. 2009). Their protein products influence CL and PE levels and protein transport in opposite ways. The loss of Ups1p decreases CL levels and the association of TIM23 translocase with the PAM complex (presequence translocase-associated motor), yet these defects are rescued by the deletion of UPS2. Ups2p also maintains mitochondrial PE levels. Ups1p and Ups2p, as well as their homolog Ups3p/Gep2p, are each associated with another IMS protein, Mdm35, required for their import and maintenance in the IMS (Tamura et al. 2009; Potting et al. 2010). The phenotype of $\Delta m d m 35$ is similar to $\Delta u p s 1 \Delta u p s 2 \Delta u p s 3$ and restoration of Ups protein levels in $\Delta m d m 35$ mitochondria does not restore PL metabolism. Hence, Mdm35p is not only mediating affinity-driven protein import, but is also a functional component of Ups-Mdm35p complexes.

The $\Delta m d m 35$ mutant was first described as having large spherical mitochondria, similar to those of the tubulation mutants (Dimmer et al. 2002). Indeed, Ups1p and Ups2p were also found to link PL regulation to morphogenesis, having partially overlapping but distinct roles in mitochondrial shape maintenance. However, in contrast to $\Delta m d m 35$, mitochondria in $\Delta u p s 1$ cells cultivated in glucose media form short tubules, small fragments, and aggregates, while in $\Delta$ ups 2 cells, only a fraction of mitochondria is disorganized into round structures, small nets, or aggregates. In contrast, in a medium with non-fermentable carbon sources, both mutants have higher CL levels than in a glucose medium and their mitochondrial morphology is tubular as in wild-type cells (Sesaki et al. 2006; Tamura et al. 2009).

The lipid supply to mitochondria presumably links also the vesicular trafficking system to mitochondrial morphogenesis. Inhibited expression of any of 35 essential genes involved in protein translocation into the ER or in vesicle budding and fusion consistently results in fragmented and/or aggregated mitochondria (Altmann and Westermann 2005).

In addition to the amount of the individual PL types, the character of fatty acyls in the PL influences many traits of these organelles. A termosensitive mutation in OLE1/MDM2 leads to their aggregation and strongly impairs their mobility into bud (McConnell et al. 1990; Stewart and Yaffe 1991). Since OLE1 encodes a fatty acid desaturase (Stukey et al. 1990), the addition of oleic acid into the growth medium restores the wild-type phenotype in the $\Delta$ ole 1 mutant (Stewart and Yaffe 1991). The fluidity (or even other properties dependent on fatty acyls) of mitochondrial membranes hence affect the distribution of these organelles.

Three hypotheses describe possible bases of this effect (Stewart and Yaffe 1991). First, their movement could be extremely sensitive to changes of the membrane fluidity. Second, the OMM protein complex interacting with cytoskeleton might depend on the nearby lipid milieu. Third, the mitochondrial movement might require some specific morphological changes which could depend on the amount of unsaturated fatty acyls in the mitochondrial PL.

Moreover, the unique lipid composition of the OMM contributes to the selectivity of the post-translational insertion of Fis1p, and presumably other OMM tail-anchored proteins, into the membrane (Kemper et al. 2008). This class of proteins is characterised by a single transmembrane region at the $\mathrm{C}$-terminus and a large $\mathrm{N}$-terminal portion exposed to the cytosol (Wattenberg and Lithgow 2001; Borgese et al. 2003). Their insertion does not involve any of the known import machineries, but might be enhanced by so far unidentified protein(s). Alternatively, certain lipid domains or 
other structural elements might be sufficient for membrane stabilization of the protein (Kemper et al. 2008). Fis1p is one of the crucial components of the mitochondrial fission complex (Mozdy et al. 2000; Zhang and Chan 2007). Division of the mitochondrial reticulum involves constriction of the tubule by a spiral of oligomerized dynamin-related GTPase, Dnm1p. Dnm 1p oligomers are stably retained on the OMM only through interactions with one of the adaptor proteins, Mdv1p or Caf4p, which are tethered to the OMM via Fis1p. It is therefore conceivable that certain disturbances of the OMM lipid profile may lead to morphological changes of the organelle due to the impairment of its fission by weakening the Mdv1p/Caf4p-Dnm1p complex anchoring.

The opposite process to fission, i.e. fusion, also displays certain requirements for membrane lipids, although these seem to contribute in a different way. Generally, besides protein machinery, most, if not all, membrane fusion events require a specific change of the lipid environment, i.e. the presence of a so-called fusogenic lipid. A typical example is phosphatidic acid, which facilitates stereotypical changes in membrane curvature that thermodynamically favour deformation and bilayer mixing, or may recruit or activate some fusion proteins (Chernomordik et al. 2006).

So far, more insights into the yeast mitochondrial fusion's requirements for membrane lipids came only from the study of Mgm1p, one of the components of the fusion complex. This dynamin-like GTPase (Guan et al. 1993; Shepard and Yaffe 1999 ) is present in two forms, both indispensable for IMM fusion and cristae formation (Herlan et al. 2003; Wong et al. 2003; Meeusen et al. 2006). The peripheral, IMM-associated short form (s-Mgm1p) is generated by the rhomboid protease Pcplp/Rbd1p from the long form (l-Mgm1p) during an unconventional processing termed alternative topogenesis (Herlan et al. 2003; McQuibban et al. 2003; Herlan et al. 2004). In vitro, s-Mgm1p assembles into trimers on liposomes and induces their aggregation. These observations suggest that s-Mgm 1 trimers on opposing membranes might stack onto each other, the following GTP hydrolysis and induction of a conformational change lead to fusion of the bilayers and subsequent release of the stacked trimers (Rujiviphat et al. 2009). Moreover, the CL-dependent in trans heterodimerization of the long isoform 1-Mgm1p with s-Mgm1p promotes higherorder assemblies and GTP-dependent conformational changes of s-Mgm1p that are needed to destabilize lipid bilayers for fusion (DeVay et al. 2009). Similarly to other dynamin proteins, stimulation of s-Mgm1p's GTPase activity requires binding to negatively charged IMM lipids (Rujiviphat et al. 2009).

\section{Ergosterol supply}

Mitochondria in cells depleted of either of the 11 essential enzymes of the ergosterol biosynthesis pathway (Table 1) are spherical (perhaps swollen), so this sterol is probably re- quired for their correct morphogenesis (Altmann and Westermann 2005). Since the ergosterol content in mitochondrial membranes is very low ( 6 and $25 \mu \mathrm{g} / \mathrm{mg}$ of organellar protein in the OMM and IMM, respectively, compared to approx. $400 \mu \mathrm{g} / \mathrm{mg}$ in the plasma membrane) (Zinser et al. 1993), its effect on their overall physical properties is very unlikely. A similar situation is encountered in vacuoles where ergosterol (present at $49 \mu \mathrm{g} / \mathrm{mg}$ ) is needed for the priming step of vacuolar homotypic fusion (Kato and Wickner 2001). It has been suggested that this lipid specifically activates and/or rearranges membrane proteins involved in the fusion reaction (Kato and Wickner 2001; Fratti et al. 2004). Analogously, it might modulate the activity of the mitochondria-shaping proteins (Altmann and Westermann 2005).

Among the nonessential proteins involved in the ergosterol synthesis, Erg6p, Erg24p, and Erg28p were shown to influence mitochondrial morphogenesis (Dimmer et al. 2002). The absence of any of them causes fragmentation and/or aggregation of mitochondria in a large fraction of cell population.

\section{Mitochondrial inheritance}

Mitochondrial biogenesis is an ongoing process, but never begins de novo; hence these organelles have to be properly segregated during every cellular division. Their distribution is closely related to the cell cycle progression (Simon et al. 1997). Together with bud-tip and mother-tip anchoring (Simon et al. 1997), anterograde (toward the bud) and retrograde (toward the mother cell tip) movements result in proper mitochondrial segregation during cell division (Fehrenbacher et al. 2004).

The mitochondrial motility can be affected by mutations in a large number of genes, many encoding components of the organellar transport system. The poleward movement is actin cable-dependent and uses the forces of actin polymerization and actin dynamics mediated by the Arp $2 / 3$ complex (Boldogh et al. 2001). This complex is linked to the OMM via Jsn1p, while Puf3p links it to the mitochore (Fehrenbacher et al. 2005; Garcia-Rodriguez et al. 2007). When Puf3p is absent, the interaction between the mitochore and the Arp2/3 complex is reduced, but appears not to be completely abolished (Garcia-Rodriguez et al. 2007), possibly due to the presence of other linking proteins. When either of ARP2, ARP3, JSN1, or PUF3 is mutated, mitochondria exhibit not only defects in anterograde movement, but also fragmentation and aggregation.

The retrograde movement relies on a different mechanism. Mitochondria bind to actin cables via the mitochore and move toward the mother cell tip (Fehrenbacher et al. 2004). At the bud tip, the actin polymerization is mediated by the formin Bnilp, which also recruits Num 1p to these active sites of cytoskeletal assembly. Num1p binds to the plasma 
membrane via phosphatidylinositol (4,5)-bisphosphate and interacts with Dnmlp (Cerveny et al. 2007). This interaction probably helps to anchor fission-undergoing mitochondria at the bud tip to generate shorter fragments, which are then attached to growing actin cables and transported back to the mother cell (Schauss and McBride 2007).

To retain mitochondria at the bud, the cell uses type $\mathrm{V}$ myosin Myo2p and its two binding partners, Ypt11p and Mmr1p (Itoh et al. 2002, 2004). Myo2p probably transports mitochondrial retention factors to the bud tip and Ypt11p and Mmrlp might be either the retention factors themselves, or adaptor molecules that link retention factors to the molecular motor (Boldogh et al. 2005). These are not the only proteins with yet precisely undetermined role in mitochondrial inheritance and morphology. Among others, the intermediate filament protein Mdm1p specifically binds membrane phosphatidylinositol 3-phosphate and this interaction is required for proper nuclear and mitochondrial transmission to buds (Fisk and Yaffe 1997; Yu and Lemmon 2001).

Mutations in genes encoding formins lead to small, round, non-tubular mitochondria (Fehrenbacher et al. 2004). While acute depolymerization of actin cables has little effect, prolonged perturbation leads to clustered and/or coalesced mitochondria (Griparic and van der Bliek 2001; Boldogh and Pon 2007). Furthermore, defects in mitochondrial inheritance caused by the absence of any mitochore component lead to the inhibition of cytokinesis which prevents reduction of the mitochondrial segregation fidelity (Garcia-Rodriguez et al. 2009). This phenotype, multiple buds lacking mitochondria, but containing nuclei, was also observed in the case of the temperature-sensitive ole 1 mutant under restrictive temperature (McConnell et al. 1990).

\section{Mitochondrial shape and ion homeostasis}

The IMM has a relatively low permeability for inorganic ions, but the $\Delta \Psi(\sim 150-180 \mathrm{mV})$ is a very potent driving force for the electrophoretic influx of cations (mainly $\mathrm{K}^{+}$and $\mathrm{Mg}^{2+}$ ) (Brown and Brand 1986). Once the osmolarity of the matrix starts to increase, it is compensated by water leakage through the IMM, hence the mitochondrion swells. To prevent such volume changes and the eventual lysis of the organelle, several ion transporters operate in the IMM. These constitute an effective homeostatic mechanism controlling ion concentrations together with matrix and IMS volumes which are essential for structural as well as functional integrity of mitochondria (Garlid and Paucek 2003; Kaasik et al. 2007). Appropriate ion concentrations are also required for mtDNA replication and stability and for intron excision (Kovac et al. 1982; Kovac and Klobucnikova 1983; Wiesenberger et al. 1992).

The transport systems have been extensively studied for decades, mainly in mammalian heart cells where they are involved in several physiological and patophysiological processes (Garlid et al. 2003). However, in yeast, only five genes are known to code for a mitochondrial cation transporter or its component: the $\mathrm{Mg}^{2+}$ channels Mrs2p (Kolisek et al. 2003; Schindl et al. 2007) and Lpe10p (Gregan et al. 2001), the Fe ${ }^{2+}$ transporters Mrs3p and Mrs4p (Muhlenhoff et al. 2003), and the $\mathrm{K}^{+} / \mathrm{H}^{+}$antiporter component Mdm38p (see below).

\section{Mitochondrial potassium transport}

The main intracellular cation $\mathrm{K}^{+}$is present in the matrix at $140-150 \mathrm{mmol} / \mathrm{l}$ which is not very different from its cytosolic concentration. Due to such high concentration, it is the main mitochondrial osmoregulator. The $\mathrm{K}^{+}$efflux from the matrix is mediated by a $\mathrm{K}^{+} / \mathrm{H}^{+}$antiporter, thus at the expense of the $\Delta \mathrm{pH}$. The unselective $\mathrm{K}^{+} / \mathrm{H}^{+}$antiport at the yeast IMM is also able to transport $\mathrm{Na}^{+}$, since a mitochondrial sodium-specific antiporter is absent (Welihinda et al. 1993). It depends on Mdm38p whose depletion leads to low $\Delta \Psi$, impaired growth on respiratory substrates, low content of respiratory complexes III and IV, and selective autophagy of the swollen organelles (Frazier et al. 2006; Nowikovsky et al. 2007). The protein is alternatively termed Mkh1 (for mitochondrial $\mathrm{K}^{+} / \mathrm{H}^{+}$exchange factor).

The defects in respiratory chain biogenesis were first attributed to matrix swelling. Yet, Mdm38p also associates with mitochondrial ribosomes (Frazier et al. 2006) and participates in the recruitment of their regulatory components; this function is crucial for the stabilization and translation of specific mRNAs encoding respiratory chain components (Bauerschmitt et al. 2010). The facilitation of co-translational membrane insertion occurs in cooperation with another IMM-associated protein, Mba1, and does not depend on the role of Mdm38p in ion homeostasis (Bauerschmitt et al. 2010).

In a genome-wide screen, four multicopy suppressors of the reduced growth of $\Delta m d m 38$ on a non-fermentable substrate were identified, all implicated in mitochondrial ion transport (Zotova et al. 2010). The genes PIC2 and MRS3 encoding IMM carriers, involved in $\mathrm{P}_{\mathrm{i}}$ transport and $\mathrm{Fe}^{2+}$ accumulation, respectively (Muhlenhoff et al. 2003; Hamel et al. 2004), are moderate, while the MRS7 and YDL183c are strong suppressors of the MDM38 deletion. In contrast to Pic2p or Mrs3p, the overproduction of Ydl183cp or Mrs7p fully restores the $\mathrm{K}^{+} / \mathrm{H}^{+}$ activity in $\Delta m d m 38$ mitochondria (Zotova et al. 2010).

Even though the human ortholog LETM1 can complement deletion of MDM38 in yeast (Froschauer et al. 2005) and the down-regulation of LETM1 also leads to disruption of both mitochondrial ion homeostasis and tubular shape, it does not influence the content of respiratory chain complexes (Dimmer et al. 2008). Moreover, fibroblasts from a patient with monoallelic deletion of LETM1 did not display morphological changes of mitochondria (Dimmer et al. 2008). The supposed role of Mdm38p/LETM1 remains questionable 
also because its homolog from Drosophila melanogaster was shown to specifically mediate coupled $\mathrm{Ca}^{2+} / \mathrm{H}^{+}$exchange in vivo and in liposomes (Jiang et al. 2009).

\section{Ionophore resistance and mitochondrial morphology}

The role of IMM cation antiporters in the prevention of matrix swelling implies that their dysfunction will affect the shape of the IMM and presumably of the entire organelle. Indeed, $\Delta m d m 38$ was originally named according to the morphological defects of its mitochondria. Due to their increased $\mathrm{K}^{+}$content, these are enlarged with very few branches, often forming rings or lariat-like structures (Dimmer et al. 2002), and devoid of tubular cristae (Nowikovsky et al. 2004; Froschauer et al. 2005). An artificial $\mathrm{K}^{+} / \mathrm{H}^{+}$antiporter nigericin can restore the respiratory growth of the $\Delta m d m 38$ mutant as well as the aberrant mitochondrial morphology of mammalian cells with down-regulated LETM1 gene, acting like a chemical suppressor of the absence of the $\mathrm{K}^{+} / \mathrm{H}^{+}$antiport (Nowikovsky et al. 2004, 2007; Dimmer et al. 2008).

Nigericin belongs to 'mobile carrier' type of ionophores, compounds catalyzing ion transfer across membranes (Nicholls and Ferguson 2001). Nigericin mediates an electrically neutral $\mathrm{K}^{+} / \mathrm{H}^{+}$exchange; it therefore dissipates $\Delta \mathrm{pH}$ but not $\Delta \Psi$ on the IMM. In mammalian cells, it was shown to cause alkalinization of intracellular vesicles/compartments. Another potassium ionophore, valinomycin, catalyses an electrical uniport of $\mathrm{K}^{+}$down its concentration gradient: outwards across the plasma membrane and inwards across the IMM of intact cells. By collapsing the mitochondrial $\mathrm{K}^{+}$gradient, valinomycin decreases $\Delta \Psi$ and causes matrix swelling (Safiulina et al. 2006).

Both valinomycin and nigericin inhibit growth of S. cerevisiae on a non-fermentable carbon source, while in conditions allowing fermentation, they induce formation of respiratory-deficient mutants (Kovac and Klobucnikova 1983). In this yeast, they act preferentially on the IMM, without affecting functions of the plasma membrane (Kovac et al. 1982). Ionophore-mediated transport depends on membrane lipid composition, but it is not clear whether the differences between mitochondrial and plasma membrane lipids alone could be the reason of this different sensitivity to valinomycin and nigericin.

As shown in our laboratory, S. cerevisiae clones resistant to either ionophore arise spontaneously at a relatively high frequency $\left(5 \times 10^{-5}\right)$ (Petrezselyova et al. 2007). This suggests that a simple mutation within a rather broad gene repertoire leads to considerable changes allowing the cell to survive and to respire in the presence of an ionophore. Analysis of such mutants could provide new insights into cellular ion homeostasis, as well as other related processes. In line with this assumption, we identified $\Delta m d m 31$ and $\Delta m d m 32$ among disruption mutants resistant to nigericin and their giant spherical mitochondria were shown to be swollen due to disturbed ion homeostasis (Kucejova et al. 2005). As their matrix $\mathrm{Mg}^{2+}$ concentration $\left[\mathrm{Mg}^{2+}\right]_{\mathrm{m}}$ is increased and nigericin is able to alleviate their morphological defects, it is possible that in the absence of Mdm31p or Mdm32p, the excess of $\mathrm{Mg}^{2+}$ inhibits the $\mathrm{K}^{+} / \mathrm{H}^{+}$antiporter, which is then unable to deal with the $\mathrm{K}^{+}$influx (Kucejova et al. 2005).

Our screening of UV-induced nigericin and valinomycin resistant mutants yielded four independent clones, $v_{a l}{ }^{\mathrm{R}}-1,2$ and $\mathrm{val} / \mathrm{nig}^{\mathrm{R}}-1,2$, with disturbed mitochondrial morphology, one of them having also vacuolar defects (Petrezselyova et al. 2007). Analogically to $\Delta m d m 31$ and $\Delta m d m 32$, fragmented mitochondria of these four strains are converted to extended tubules during incubation in the presence of valinomycin or nigericin. Hence, the restoration of standard mitochondrial shape by targeting ion homeostasis surprisingly turned out not to be limited to mutants with apparently swollen mitochondria.

\section{Conclusions}

The shape of mitochondrial reticulum depends on permanent fission and fusion events which adapt it in line with actual cellular needs into an extended tubular or fragmented form. Proteins directly responsible for the fission or fusion have been identified; their complex regulation is being investigated. However, so far, all proteins whose absence results in large spherical mitochondria were recognized to be primarily involved in mitochondrial biogenesis or ion homeostasis. Although the supply of certain shape proteins and particular lipids influencing membrane properties, together with prevention of matrix swelling, contribute to the mitochondrial shape maintenance in a conceivable way, the exact mechanism molding the two membranes into tubules remains unknown. Besides further examination of the identified tubulation mutants and search for eventual new ones, detailed microscopic time-course observations of tubulation itself (e.g. transformation of a big swollen mitochondrion of a conditional mutant into a tubule after transfer to a permissive temperature) could lead to a better understanding of the process.

Acknowledgements. I wish to thank Lubomir Tomaska and Matus Valach (Comenius University) for critical reading of the manuscript. I apologize to authors whose work was not cited due to space limitations. Our work related to sensitivity to ionophores is supported by grants from the Slovak grant agencies APVV (VVCE-0064-07; 002407) and VEGA (1/0132/09) (L.T.). L. A. has no conflict of interest and no financial interest in the publication of this manuscript.

\section{References}

Altmann K., Westermann B. (2005): Role of essential genes in mitochondrial morphogenesis in Saccharomyces cerevisiae. Mol. Biol. Cell 16, 5410-5417 doi:10.1091/mbc.E05-07-0678 
Bauerschmitt H., Mick D. U., Deckers M., Vollmer C., Funes S., Kehrein K., Ott M., Rehling P., Herrmann J. M. (2010): Ribosome-binding proteins Mdm38 and Mbal display overlapping functions for regulation of mitochondrial translation. Mol. Biol. Cell 21, 1937-1944 doi:10.1091/mbc.E10-02-0101

Benard G., Bellance N., James D., Parrone P., Fernandez H., Letellier T., Rossignol R. (2007): Mitochondrial bioenergetics and structural network organization. J. Cell Sci. 120, 838-848 doi: $10.1242 /$ jcs. 03381

Bereiter-Hahn J., Voth M. (1994): Dynamics of mitochondria in living cells: shape changes, dislocations, fusion, and fission of mitochondria. Microsc. Res. Tech. 27, 198-219 doi:10.1002/jemt.1070270303

Berger K. H., Sogo L. F., Yaffe M. P. (1997): Mdm12p, a component required for mitochondrial inheritance that is conserved between budding and fission yeast. J. Cell Biol. 136, 545-553 doi:10.1083/jcb.136.3.545

Berger K. H., Yaffe M. P. (1998): Prohibitin family members interact genetically with mitochondrial inheritance components in Saccharomyces cerevisiae. Mol. Cell. Biol. 18, 4043-4052

Birner R., Nebauer R., Schneiter R., Daum G. (2003): Synthetic lethal interaction of the mitochondrial phosphatidylethanolamine biosynthetic machinery with the prohibitin complex of Saccharomyces cerevisiae. Mol. Biol. Cell 14, 370-383 doi:10.1091/mbc.E02-05-0263

Boldogh I. R., Yang H. C., Nowakowski W. D., Karmon S. L., Hays L. G., Yates J. R., 3rd, Pon L. A. (2001): Arp2/3 complex and actin dynamics are required for actin-based mitochondrial motility in yeast. Proc. Natl. Acad. Sci. U.S.A. 98, 3162-3167 doi:10.1073/pnas.051494698

Boldogh I. R., Nowakowski D. W., Yang H. C., Chung H., Karmon S., Royes P., Pon L. A. (2003): A protein complex containing Mdm10p, Mdm12p, and Mmm1p links mitochondrial membranes and DNA to the cytoskeleton-based segregation machinery. Mol. Biol. Cell 14, 4618-4627 doi:10.1091/mbc.E03-04-0225

Boldogh I. R., Fehrenbacher K. L., Yang H. C., Pon L. A. (2005): Mitochondrial movement and inheritance in budding yeast. Gene 354, 28-36 doi:10.1016/j.gene.2005.03.049

Boldogh I. R., Pon L. A. (2007): Mitochondria on the move. Trends Cell Biol. 17, 502-510 doi:10.1016/j.tcb.2007.07.008

Borgese N., Brambillasca S., Soffientini P., Yabal M., Makarow M. (2003): Biogenesis of tail-anchored proteins. Biochem. Soc. Trans. 31, 1238-1242 doi:10.1042/BST0311238

Brown G. C., Brand M. D. (1986): Changes in permeability to protons and other cations at high proton motive force in rat liver mitochondria. Biochem. J. 234, 75-81

Cerveny K. L., Studer S. L., Jensen R. E., Sesaki H. (2007): Yeast mitochondrial division and distribution require the cortical num1 protein. Dev. Cell 12, 363-375 doi:10.1016/j.devcel.2007.01.017

Chan D. C. (2006): Mitochondria: dynamic organelles in disease, aging, and development. Cell 125, 1241-1252 doi:10.1016/j.cell.2006.06.010
Chen H., Chomyn A., Chan D. C. (2005): Disruption of fusion results in mitochondrial heterogeneity and dysfunction. J. Biol. Chem. 280, 26185-26192 doi:10.1074/jbc.M503062200

Chen H., Chan D. C. (2009): Mitochondrial dynamics--fusion, fission, movement, and mitophagy--in neurodegenerative diseases. Hum. Mol. Genet. 18, R169-176 doi:10.1093/hmg/ddp326

Chernomordik L. V., Zimmerberg J., Kozlov M. M. (2006): Membranes of the world unite! J. Cell Biol. 175, 201-207 doi:10.1083/jcb.200607083

Detmer S. A., Chan D. C. (2007): Functions and dysfunctions of mitochondrial dynamics. Nat. Rev. Mol. Cell. Biol. 8, 870-879 doi:10.1038/nrm2275

DeVay R. M., Dominguez-Ramirez L., Lackner L. L., Hoppins S., Stahlberg H., Nunnari J. (2009): Coassembly of Mgm1 isoforms requires cardiolipin and mediates mitochondrial inner membrane fusion. J. Cell Biol. 186, 793-803 doi:10.1083/jcb.200906098

Dimmer K. S., Fritz S., Fuchs F., Messerschmitt M., Weinbach N., Neupert W., Westermann B. (2002): Genetic basis of mitochondrial function and morphology in Saccharomyces cerevisiae. Mol. Biol. Cell 13, 847-853 doi:10.1091/mbc.01-12-0588

Dimmer K. S., Jakobs S., Vogel F., Altmann K., Westermann B. (2005): Mdm31 and Mdm32 are inner membrane proteins required for maintenance of mitochondrial shape and stability of mitochondrial DNA nucleoids in yeast. J. Cell Biol. 168, 103-115 doi:10.1083/jcb.200410030

Dimmer K. S., Navoni F., Casarin A., Trevisson E., Endele S., Winterpacht A., Salviati L., Scorrano L. (2008): LETM1, deleted in Wolf Hirschhorn syndrome is required for normal mitochondrial morphology and cellular viability. Hum. Mol. Genet. 17, 201-214 doi:10.1093/hmg/ddm297

Fehrenbacher K. L., Yang H. C., Gay A. C., Huckaba T. M., Pon L. A. (2004): Live cell imaging of mitochondrial movement along actin cables in budding yeast. Curr. Biol. 14, 1996-2004 doi:10.1016/j.cub.2004.11.004

Fehrenbacher K. L., Boldogh I. R., Pon L. A. (2005): A role for Jsn1p in recruiting the Arp2/3 complex to mitochondria in budding yeast. Mol. Biol. Cell 16, 5094-5102 doi:10.1091/mbc.E05-06-0590

Fisk H. A., Yaffe M. P. (1997): Mutational analysis of Mdmlp function in nuclear and mitochondrial inheritance. J. Cell Biol. 138, 485-494 doi:10.1083/jcb.138.3.485

Fratti R. A., Jun Y., Merz A. J., Margolis N., Wickner W. (2004): Interdependent assembly of specific regulatory lipids and membrane fusion proteins into the vertex ring domain of docked vacuoles. J. Cell Biol. 167, 1087-1098 doi:10.1083/jcb.200409068

Frazier A. E., Taylor R. D., Mick D. U., Warscheid B., Stoepel N., Meyer H. E., Ryan M. T., Guiard B., Rehling P. (2006): Mdm38 interacts with ribosomes and is a component of the mitochondrial protein export machinery. J. Cell Biol. 172, 553-564 doi:10.1083/jcb.200505060 
Froschauer E., Nowikovsky K., Schweyen R. J. (2005): Electroneutral $\mathrm{K}+/ \mathrm{H}+$ exchange in mitochondrial membrane vesicles involves Yol027/Letm1 proteins. Biochim. Biophys. Acta 1711, 41-48 doi:10.1016/j.bbamem.2005.02.018

Garcia-Rodriguez L. J., Gay A. C., Pon L. A. (2007): Puf3p, a Pumilio family RNA binding protein, localizes to mitochondria and regulates mitochondrial biogenesis and motility in budding yeast. J. Cell Biol. 176, 197-207 doi: $10.1083 /$ jcb. 200606054

Garcia-Rodriguez L. J., Crider D. G., Gay A. C., Salanueva I. J., Boldogh I. R., Pon L. A. (2009): Mitochondrial inheritance is required for MEN-regulated cytokinesis in budding yeast. Curr. Biol. 19, 1730-1735 doi:10.1016/j.cub.2009.08.041

Garlid K. D., Dos Santos P., Xie Z. J., Costa A. D., Paucek P. (2003) Mitochondrial potassium transport: the role of the mitochondrial ATP-sensitive $\mathrm{K}(+)$ channel in cardiac function and cardioprotection. Biochim. Biophys. Acta 1606, 1-21 doi:10.1016/S0005-2728(03)00109-9

Garlid K. D., Paucek P. (2003): Mitochondrial potassium transport: the $\mathrm{K}(+)$ cycle. Biochim. Biophys. Acta 1606, 23-41 doi:10.1016/S0005-2728(03)00108-7

Graham T. R., Kozlov M. M. (2010): Interplay of proteins and lipids in generating membrane curvature. Curr. Opin. Cell Biol. 22, 430-436 doi:10.1016/j.ceb.2010.05.002

Gregan J., Bui D. M., Pillich R., Fink M., Zsurka G., Schweyen R. J. (2001): The mitochondrial inner membrane protein Lpe10p, a homologue of Mrs2p, is essential for magnesium homeostasis and group II intron splicing in yeast. Mol. Gen. Genet. 264, 773-781 doi:10.1007/s004380000366

Griparic L., van der Bliek A. M. (2001): The many shapes of mitochondrial membranes. Traffic 2, 235-244 doi:10.1034/j.1600-0854.2001.1r008.x

Guan K., Farh L., Marshall T. K., Deschenes R. J. (1993): Normal mitochondrial structure and genome maintenance in yeast requires the dynamin-like product of the MGM1 gene. Curr. Genet. 24, 141-148 doi:10.1007/BF00324678

Hamel P., Saint-Georges Y., de Pinto B., Lachacinski N., Altamura N., Dujardin G. (2004): Redundancy in the function of mitochondrial phosphate transport in Saccharomyces cerevisiae and Arabidopsis thaliana. Mol. Microbiol. 51, 307-317 doi:10.1046/j.1365-2958.2003.03810.x

Hanekamp T., Thorsness M. K., Rebbapragada I., Fisher E. M., Seebart C., Darland M. R., Coxbill J. A., Updike D. L., Thorsness P. E. (2002): Maintenance of mitochondrial morphology is linked to maintenance of the mitochondrial genome in Saccharomyces cerevisiae. Genetics 162, 1147-1156

Herlan M., Vogel F., Bornhovd C., Neupert W., Reichert A. S. (2003): Processing of Mgm 1 by the rhomboid-type protease Pcp1 is required for maintenance of mitochondrial morphology and of mitochondrial DNA. J. Biol. Chem. 278, 27781-27788 doi:10.1074/jbc.M211311200

Herlan M., Bornhovd C., Hell K., Neupert W., Reichert A. S. (2004): Alternative topogenesis of Mgm1 and mitochondrial morphology depend on ATP and a functional import motor. J. Cell Biol. 165, 167-173

doi:10.1083/jcb.200403022

Hobbs A. E., Srinivasan M., McCaffery J. M., Jensen R. E. (2001): $\mathrm{Mmm} 1 \mathrm{p}$, a mitochondrial outer membrane protein, is connected to mitochondrial DNA (mtDNA) nucleoids and required for mtDNA stability. J. Cell Biol. 152, 401-410 doi:10.1083/jcb.152.2.401

Hoffmann H. P., Avers C. J. (1973): Mitochondrion of yeast: ultrastructural evidence for one giant, branched organelle per cell. Science 181, 749-751 doi:10.1126/science.181.4101.749

Itoh T., Watabe A., Toh E. A., Matsui Y. (2002): Complex formation with Ypt11p, a rab-type small GTPase, is essential to facilitate the function of Myo2p, a class V myosin, in mitochondrial distribution in Saccharomyces cerevisiae. Mol. Cell. Biol. 22, 7744-7757 doi:10.1128/MCB.22.22.7744-7757.2002

Itoh T., Toh E. A., Matsui Y. (2004): Mmrlp is a mitochondrial factor for Myo2p-dependent inheritance of mitochondria in the budding yeast. EMBO J. 23, 2520-2530 doi:10.1038/sj.emboj.7600271

Jensen R. E. (2005): Control of mitochondrial shape. Curr. Opin. Cell Biol. 17, 384-388 doi:10.1016/j.ceb.2005.06.011

Jezek P., Plecita-Hlavata L. (2009): Mitochondrial reticulum network dynamics in relation to oxidative stress, redox regulation, and hypoxia. Int. J. Biochem. Cell Biol. 41, 1790-1804 doi:10.1016/j.biocel.2009.02.014

Jiang D., Zhao L., Clapham D. E. (2009): Genome-wide RNAi screen identifies Letm 1 as a mitochondrial $\mathrm{Ca} 2+/ \mathrm{H}+$ antiporter. Science 326, 144-147 doi:10.1126/science.1175145

Kaasik A., Safiulina D., Zharkovsky A., Veksler V. (2007): Regulation of mitochondrial matrix volume. Am. J. Physiol. Cell Physiol. 292, C157-163 doi:10.1152/ajpcell.00272.2006

Kato M., Wickner W. (2001): Ergosterol is required for the Sec18/ ATP-dependent priming step of homotypic vacuole fusion. EMBO J. 20, 4035-4040 doi:10.1093/emboj/20.15.4035

Kemper C., Habib S. J., Engl G., Heckmeyer P., Dimmer K. S., Rapaport D. (2008): Integration of tail-anchored proteins into the mitochondrial outer membrane does not require any known import components. J. Cell Sci. 121, 1990-1998 doi:10.1242/jcs.024034

Kolisek M., Zsurka G., Samaj J., Weghuber J., Schweyen R. J., Schweigel M. (2003): Mrs2p is an essential component of the major electrophoretic $\mathrm{Mg} 2+$ influx system in mitochondria. EMBO J. 22, 1235-1244 doi:10.1093/emboj/cdg122

Kornmann B., Currie E., Collins S. R., Schuldiner M., Nunnari J., Weissman J.S., Walter P. (2009): An ER-mitochondria tethering complex revealed by a synthetic biology screen. Science $325,477-481$ doi:10.1126/science.1175088

Kovac L., Bohmerova E., Butko P. (1982): Ionophores and intact cells. I. Valinomycin and nigericin act preferentially on mito- 
chondria and not on the plasma membrane of Saccharomyces cerevisiae. Biochim. Biophys. Acta 721, 341-348 doi:10.1016/0167-4889(82)90088-X

Kovac L., Klobucnikova V. (1983): Some ionophores act preferentially on mitochondria in intact cells of Saccharomyces cerevisiae and induce respiration-deficient mutants. In: Mitochondria. (Eds. K. R. J. Schweyen, K. Wolf and F. Kaudewitz), pp. 65-68, Walter de Gruyter, Berlin, New York

Kozlov M. M., McMahon H. T., Chernomordik L. V. (2010): Protein-driven membrane stresses in fusion and fission. Trends Biochem. Sci. 35, 699-706 doi:10.1016/j.tibs.2010.1006.1003 doi:10.1016/j.tibs.2010.06.003

Kucejova B., Kucej M., Petrezselyova S., Abelovska L., Tomaska L. (2005): A screen for nigericin-resistant yeast mutants revealed genes controlling mitochondrial volume and mitochondrial cation homeostasis. Genetics 171, 517-526 doi:10.1534/genetics.105.046540

Kuznetsov A. V., Margreiter R. (2009): Heterogeneity of mitochondria and mitochondrial function within cells as another level of mitochondrial complexity. Int. J. Mol. Sci. 10, 1911-1929 doi:10.3390/ijms10041911

Liesa M., Palacin M., Zorzano A. (2009): Mitochondrial dynamics in mammalian health and disease. Physiol. Rev. 89, 799-845 doi:10.1152/physrev.00030.2008

McConnell S. J., Stewart L. C., Talin A., Yaffe M. P. (1990): Temperature-sensitive yeast mutants defective in mitochondrial inheritance. J. Cell Biol. 111, 967-976 doi:10.1083/jcb.111.3.967

McQuibban G. A., Saurya S., Freeman M. (2003): Mitochondrial membrane remodelling regulated by a conserved rhomboid protease. Nature 423, 537-541

doi:10.1038/nature01633

Meeusen S., Nunnari J. (2003): Evidence for a two membranespanning autonomous mitochondrial DNA replisome. J. Cell Biol. 163, 503-510 doi:10.1083/jcb.200304040

Meeusen S., DeVay R., Block J., Cassidy-Stone A., Wayson S., McCaffery J. M., Nunnari J. (2006): Mitochondrial innermembrane fusion and crista maintenance requires the dynamin-related GTPase Mgm1. Cell 127, 383-395 doi:10.1016/j.cell.2006.09.021

Meisinger C., Pfannschmidt S., Rissler M., Milenkovic D., Becker T., Stojanovski D., Youngman M. J., Jensen R. E., Chacinska A., Guiard B., Pfanner N., Wiedemann N. (2007): The morphology proteins Mdm12/Mmm1 function in the major beta-barrel assembly pathway of mitochondria. EMBO J. 26, 2229-2239 doi:10.1038/sj.emboj.7601673

Meisinger C., Rissler M., Chacinska A., Szklarz L. K., Milenkovic D., Kozjak V., Schonfisch B., Lohaus C., Meyer H. E., Yaffe M. P., Guiard B., Wiedemann N., Pfanner N. (2004): The mitochondrial morphology protein Mdm10 functions in assembly of the preprotein translocase of the outer membrane. Dev. Cell 7, 61-71 doi:10.1016/j.devcel.2004.06.003

Meisinger C., Wiedemann N., Rissler M., Strub A., Milenkovic D., Schonfisch B., Muller H., Kozjak V., Pfanner N. (2006): Mitochondrial protein sorting: differentiation of beta-barrel assembly by Tom7-mediated segregation of Mdm10. J. Biol. Chem. 281, 22819-22826 doi:10.1074/jbc.M602679200

Mozdy A. D., McCaffery J. M., Shaw J. M. (2000): Dnm1p GTPase-mediated mitochondrial fission is a multi-step process requiring the novel integral membrane component Fis1p. J. Cell Biol. 151, 367-380 doi:10.1083/jcb.151.2.367

Muhlenhoff U., Stadler J. A., Richhardt N., Seubert A., Eickhorst T., Schweyen R. J., Lill R., Wiesenberger G. (2003): A specific role of the yeast mitochondrial carriers MRS3/4p in mitochondrial iron acquisition under iron-limiting conditions. J. Biol. Chem. 278, 40612-40620 doi:10.1074/jbc.M307847200

Nicholls D. G., Ferguson S. J. (2001): Ion transport across energyconserving membranes, In: Bioenergetics 3. Academic Press, San Diego

Nijtmans L. G., de Jong L., Artal Sanz M., Coates P. J., Berden J. A., Back J. W., Muijsers A. O., van der Spek H., Grivell L. A. (2000): Prohibitins act as a membrane-bound chaperone for the stabilization of mitochondrial proteins. EMBO J. 19, 2444-2451 doi:10.1093/emboj/19.11.2444

Nowikovsky K., Froschauer E. M., Zsurka G., Samaj J., Reipert S., Kolisek M., Wiesenberger G., Schweyen R. J. (2004): The LETM1/YOL027 gene family encodes a factor of the mitochondrial $\mathrm{K}+$ homeostasis with a potential role in the WolfHirschhorn syndrome. J. Biol. Chem. 279, 30307-30315 doi:10.1074/jbc.M403607200

Nowikovsky K., Reipert S., Devenish R. J., Schweyen R. J. (2007): $\mathrm{Mdm} 38$ protein depletion causes loss of mitochondrial $\mathrm{K}+\mathrm{H}+$ exchange activity, osmotic swelling and mitophagy. Cell Death Differ. 14, 1647-1656 doi:10.1038/sj.cdd.4402167

Okamoto K., Shaw J. M. (2005): Mitochondrial morphology and dynamics in yeast and multicellular eukaryotes. Annu. Rev. Genet. 39, 503-536 doi:10.1146/annurev.genet.38.072902.093019

Osman C., Haag M., Potting C., Rodenfels J., Dip P. V., Wieland F. T., Brugger B., Westermann B., Langer T. (2009): The genetic interactome of prohibitins: coordinated control of cardiolipin and phosphatidylethanolamine by conserved regulators in mitochondria. J. Cell Biol. 184, 583-596 doi: $10.1083 /$ jcb. 200810189

Paschen S. A., Neupert W., Rapaport D. (2005): Biogenesis of betabarrel membrane proteins of mitochondria. Trends Biochem. Sci. 30, 575-582

doi:10.1016/j.tibs.2005.08.009

Petrezselyova S., Lalakova J., Abelovska L., Klobucnikova V., Tomaska L. (2007): A collection of yeast mutants selectively resistant to ionophores acting on mitochondrial inner membrane. Mitochondrion 8, 117-129 doi:10.1016/j.mito.2007.10.003

Pfanner N., Wiedemann N., Meisinger C., Lithgow T. (2004): Assembling the mitochondrial outer membrane. Nat. Struct. Mol. Biol. 11, 1044-1048 doi:10.1038/nsmb852

Potting C., Wilmes C., Engmann T., Osman C., Langer T. (2010): Regulation of mitochondrial phospholipids by Ups1/PRELI- 
like proteins depends on proteolysis and Mdm35. EMBO J. 29, 2888-2898 doi:10.1038/emboj.2010.169

Ren G., Vajjhala P., Lee J. S., Winsor B., Munn A. L. (2006): The BAR domain proteins: molding membranes in fission, fusion, and phagy. Microbiol. Mol. Biol. Rev. 70, 37-120 doi:10.1128/MMBR.70.1.37-120.2006

Rujiviphat J., Meglei G., Rubinstein J. L., McQuibban G. A. (2009): Phospholipid association is essential for dynamin-related protein Mgm1 to function in mitochondrial membrane fusion. J. Biol. Chem. 284, 28682-28686 doi:10.1074/jbc.M109.044933

Safiulina D., Veksler V., Zharkovsky A., Kaasik A. (2006): Loss of mitochondrial membrane potential is associated with increase in mitochondrial volume: physiological role in neurones. J. Cell. Physiol. 206, 347-353 doi:10.1002/jcp.20476

Schauss A. C., McBride H. M. (2007): Mitochondrial fission: a nonnuclear role for Num1p. Curr. Biol. 17, R467-470 doi:10.1016/j.cub.2007.04.018

Schindl R., Weghuber J., Romanin C., Schweyen R. J. (2007): Mrs2p forms a high conductance $\mathrm{Mg} 2+$ selective channel in mitochondria. Biophys. J. 93, 3872-3883 doi:10.1529/biophysj.107.112318

Sesaki H., Dunn C. D., Iijima M., Shepard K. A., Yaffe M. P., Machamer C. E., Jensen R. E. (2006): Ups1p, a conserved intermembrane space protein, regulates mitochondrial shape and alternative topogenesis of Mgm1p. J. Cell Biol. 173, 651-658 doi:10.1083/jcb.200603092

Shepard K. A., Yaffe M. P. (1999): The yeast dynamin-like protein, Mgm1p, functions on the mitochondrial outer membrane to mediate mitochondrial inheritance. J. Cell Biol. 144, 711-720 doi:10.1083/jcb.144.4.711

Shibata Y., Hu J., Kozlov M. M., Rapoport T. A. (2009): Mechanisms shaping the membranes of cellular organelles. Annu. Rev. Cell Dev. Biol. 25, 329-354 doi:10.1146/annurev.cellbio.042308.113324

Simon V. R., Karmon S. L., Pon L. A. (1997): Mitochondrial inheritance: cell cycle and actin cable dependence of polarized mitochondrial movements in Saccharomyces cerevisiae. Cell Motil. Cytoskeleton 37, 199-210 doi:10.1002/(SICI) 1097-0169(1997)37:3<199::AID -CM2>3.0.CO;2-2

Sogo L. F., Yaffe M. P. (1994): Regulation of mitochondrial morphology and inheritance by Mdm10p, a protein of the mitochondrial outer membrane. J. Cell Biol. 126, 1361-1373 doi:10.1083/jcb.126.6.1361

Steglich G., Neupert W., Langer T. (1999): Prohibitins regulate membrane protein degradation by the $\mathrm{m}$-AAA protease in mitochondria. Mol. Cell. Biol. 19, 3435-3442

Stewart L. C., Yaffe M. P. (1991): A role for unsaturated fatty acids in mitochondrial movement and inheritance. J. Cell Biol. 115, 1249-1257 doi: $10.1083 /$ jcb.115.5.1249

Stukey J. E., McDonough V. M., Martin C. E. (1990): The OLE1 gene of Saccharomyces cerevisiae encodes the delta 9 fatty acid desaturase and can be functionally replaced by the rat stearoylCoA desaturase gene. J. Biol. Chem. 265, 20144-20149
Tamura Y., Endo T., Iijima M., Sesaki H. (2009): Ups1p and Ups2p antagonistically regulate cardiolipin metabolism in mitochondria. J. Cell Biol. 185, 1029-1045 doi:10.1083/jcb.200812018

Wattenberg B., Lithgow T. (2001): Targeting of C-terminal (tail)anchored proteins: understanding how cytoplasmic activities are anchored to intracellular membranes. Traffic 2, 66-71 doi:10.1034/j.1600-0854.2001.20108.x

Welihinda A. A., Trumbly R. J., Garlid K. D., Beavis A. D. (1993): On the regulation of $\mathrm{Na}+\mathrm{H}+$ and $\mathrm{K}+/ \mathrm{H}+$ antiport in yeast mitochondria: evidence for the absence of an $\mathrm{Na}(+)$-selective $\mathrm{Na}+\mathrm{H}+$ antiporter. Biochim. Biophys. Acta 1144, 367-373 doi:10.1016/0005-2728(93)90122-V

Wiesenberger G., Waldherr M., Schweyen R. J. (1992): The nuclear gene MRS2 is essential for the excision of group II introns from yeast mitochondrial transcripts in vivo. J. Biol. Chem. 267, 6963-6969

Wong E. D., Wagner J. A., Scott S. V., Okreglak V., Holewinske T. J., Cassidy-Stone A., Nunnari J. (2003): The intramitochondrial dynaminrelated GTPase, Mgm1p, is a component of a protein complex that mediates mitochondrial fusion. J. Cell Biol. 160, 303-311 doi:10.1083/jcb.200209015

Yamano K., Tanaka-Yamano S., Endo T. (2010): Mdm10 as a dynamic constituent of the TOB/SAM complex directs coordinated assembly of Tom40. EMBO Rep. 11, 187-193 doi:10.1038/embor.2009.283

Youngman M. J., Hobbs A. E., Burgess S. M., Srinivasan M., Jensen R. E. (2004): Mmm2p, a mitochondrial outer membrane protein required for yeast mitochondrial shape and maintenance of mtDNA nucleoids. J. Cell Biol. 164, 677-688 doi: $10.1083 /$ jcb.200308012

Yu J. W., Lemmon M. A. (2001): All phox homology (PX) domains from Saccharomyces cerevisiae specifically recognize phosphatidylinositol 3-phosphate. J. Biol. Chem. 276, 44179-44184 doi:10.1074/jbc.M108811200

Zhang Y., Chan D. C. (2007): Structural basis for recruitment of mitochondrial fission complexes by Fis1. Proc. Natl. Acad. Sci. U.S.A 104, 18526-18530 doi:10.1073/pnas.0706441104

Zheng Y. Z., Berg K. B., Foster L. J. (2009): Mitochondria do not contain lipid rafts, and lipid rafts do not contain mitochondrial proteins. J. Lipid Res. 50, 988-998 doi:10.1194/jlr.M800658-JLR200

Zinser E., Paltauf F., Daum G. (1993): Sterol composition of yeast organelle membranes and subcellular distribution of enzymes involved in sterol metabolism. J. Bacteriol. 175, 2853-2858

Zorzano A., Liesa M., Sebastian D., Segales J., Palacin M. (2010): Mitochondrial fusion proteins: dual regulators of morphology and metabolism. Semin. Cell Dev. Biol. 21, 566-574 doi:10.1016/j.semcdb.2010.01.002

Zotova L., Aleschko M., Sponder G., Baumgartner R., Reipert S., Prinz M., Schweyen R. J., Nowikovsky K. (2010): Novel components of an active mitochondrial $\mathrm{K}(+) / \mathrm{H}(+)$ exchange. J. Biol. Chem. 285, 14399-14414 doi:10.1074/jbc.M109.059956

Received: October 15, 2010

Final version accepted: January 19, 2011 